\title{
Potential pitfalls in the anorectal region during CT colonography: A discussion and pictorial overview of common pitfalls
}

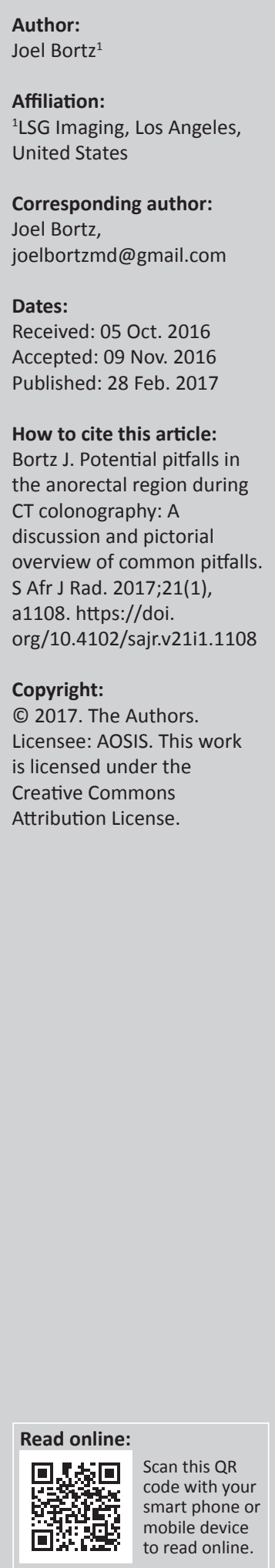

Common potential anorectal pitfalls are presented with accompanying CT colonography images. Although most lesions are benign, care must be taken in not missing an underlying cancer.

\section{Introduction}

It is highly likely that requests for computer tomographic colonography (CTC) will increase because it was very recently added to the colorectal cancer screening tests in the United States. ${ }^{1} \mathrm{~A}$ steep learning curve exists for CTC. ${ }^{2}$ There are many entities in the anorectal region, which may cause interpretation problems for those with limited CTC experience. ${ }^{3,4}$ Most findings do not require further investigation and may require just a digital rectal examination or anoscopy without the need for an optical colonoscopy (OC). ${ }^{3}$ CTC is a minimally invasive, fast, safe, lowdose and accurate study. ${ }^{5}$ An adequately prepared bowel with good distension of the colon is essential to achieve a successful study. ${ }^{3}$

Based on the author's experience, having performed > 6000 CTC examinations, the most common technical-related potential pitfalls (placement of the rectal catheter, stool and artefacts) and pathology-related pitfalls (internal haemorrhoids, polyps, cancer, hypertrophied anal papilla, perforation because of OC complications, and extrinsic impressions) are described with CTC images. ${ }^{2,4,6,7,8}$ In female patients, it is essential to always check that the catheter is in the rectum and not in the vagina before commencing insufflation. ${ }^{9}$

\section{Rectum anatomy}

The rectum is mostly a retroperitoneal organ commencing at the mid-sacral level and ending in the anal canal; its average length is $15 \mathrm{~cm}$. It does not have haustral markings. The longitudinal taenia coli end at the rectosigmoid junction and continue only as a smooth muscle layer in the rectum..$^{10}$ The three valves of Houston (superior, middle and inferior) encircle about a third to a half of the rectal circumference. ${ }^{11}$ In a CTC study, the middle valve may serve as a landmark for the location of lesions in the rectum (Figure 1). It indicates the level of the abdominoperitoneal reflection anteriorly; it is typically $8 \mathrm{~cm}$ from the anal verge and demarcates the lower and middle third of the rectum. ${ }^{11}$ The dentate line (Figure 2) represents the anatomic anorectal line, which is identified by an undulating demarcation in the rectal mucosa about 3 $\mathrm{cm}$ above the anal verge. ${ }^{10}$

\section{Technical-related pitfalls}

A rectal catheter can cause interpretation problems. ${ }^{12}$ It is preferable to use a small gauge $(25 \mathrm{Fr}$ or smaller) disposable flexible latex-free catheter, with an inflatable balloon, ${ }^{13}$ which can be distended up to $50 \mathrm{cc}$ without the risk of the balloon rupturing (Figure 3). The catheter may obscure pathology in some patients. ${ }^{6}$ To minimise this potential pitfall, it is important to deflate the balloon in the prone view: (1) to obtain a full scan series without an inflated balloon, to ensure good visualisation of the distal rectum, and (2) to better visualise internal haemorrhoids, if present. 6,9

Figures 4 to 6 illustrate several catheter-related pitfalls. The catheter may impinge on the valve of Houston causing an extrinsic impression. If $\mathrm{CO}_{2}$ flow is obstructed by any cause, deflate the balloon, pull back on the catheter until flow resumes and then re-inflate the balloon. An inflated balloon may cause a defect called the meniscus sign; ${ }^{14}$ this is a normal artefact which 


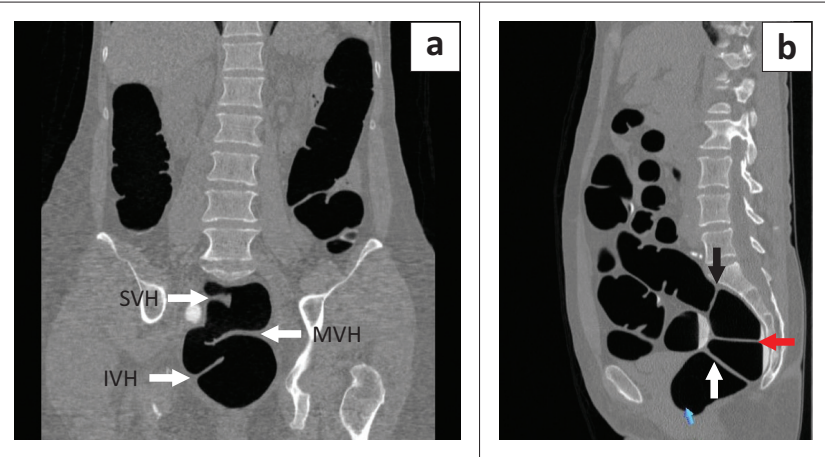

SVH, superior valves of Houston; $\mathrm{MVH}$, middle valves of Houston; IVH, inferior valves of Houston FIGURE 1: (a) 2D coronal view showing inferior, middle and superior valves of Houston. (b) 2D sagittal view showing the three valves of Houston in the rectum: superior (black arrow), middle (red arrow), inferior (white arrow).

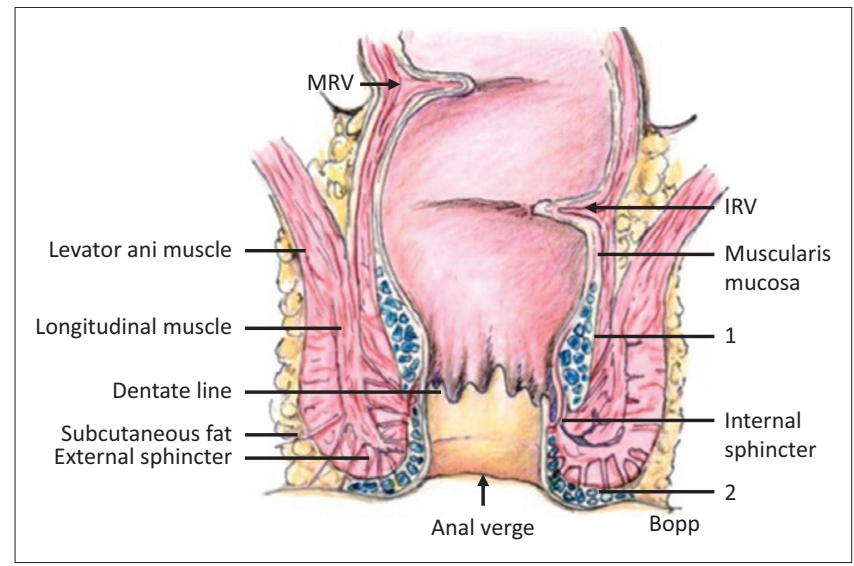

Source: Adapted from Netter F. The Ciba collection of medical illustrations. Vol 3. Digestive system. Part 2. Lower digestive tract. New York: Colour Press, 1962, p 58

$\mathrm{MVH}$, middle valves of Houston; IVH, inferior valves of Houston.

FIGURE 2: Anatomy of rectum: Middle rectal fold of valve of Houston and inferior rectal fold of valve of Houston: 1 , submucosal space and internal haemorrhoidal plexus; 2 , external haemorrhoidal plexus in peri-anal space. is depicted in Figure 7.2D and 3D views are complementary, and if available translucent display (TD) shows what lies beneath the surface. This software displays different colour attenuation values: red indicates soft tissue; white indicates high attenuation values, such as barium; green indicates negative values in the fat attenuation range; and blue indicates negative values, such as air. ${ }^{14}$

Occasionally, the rectal tube itself may obscure a sessile polyp in the rectum. The author's standard technique is to perform a $360^{\circ}$ fly around the rectal catheter to ensure adequate visualisation of all surrounding features. Incomplete collapse of the balloon may cause artefacts that appear as polypoidal lesions.

Artefacts are an unwanted feature on a CTC image that may obscure or simulate pathology. ${ }^{15}$ The presence of residual stool remaining after a laxative preparation may present interpretation challenges. Fluid and stool tagging reduces such challenges. ${ }^{6,16}$ Untagged luminal fluid will not appear white on the $2 \mathrm{D}$ views, which means that if a lesion is present it will not be apparent. Tagging with iodinated contrast (e.g. gastrografin or iohexol) enables lesions in fluid to be easily identified using windowing (W:2000 HU, L: $0 \mathrm{HU})$. A two-view series allows evaluation of the anterior and posterior walls because of shifting of fluid in these positions.

Figure 8 illustrates some stool-related pitfalls. Stool may present as a polypoidal lesion on 3D endoluminal flythrough. It may move to the dependant bowel surface between the two-view study (supine and prone), which differentiates it

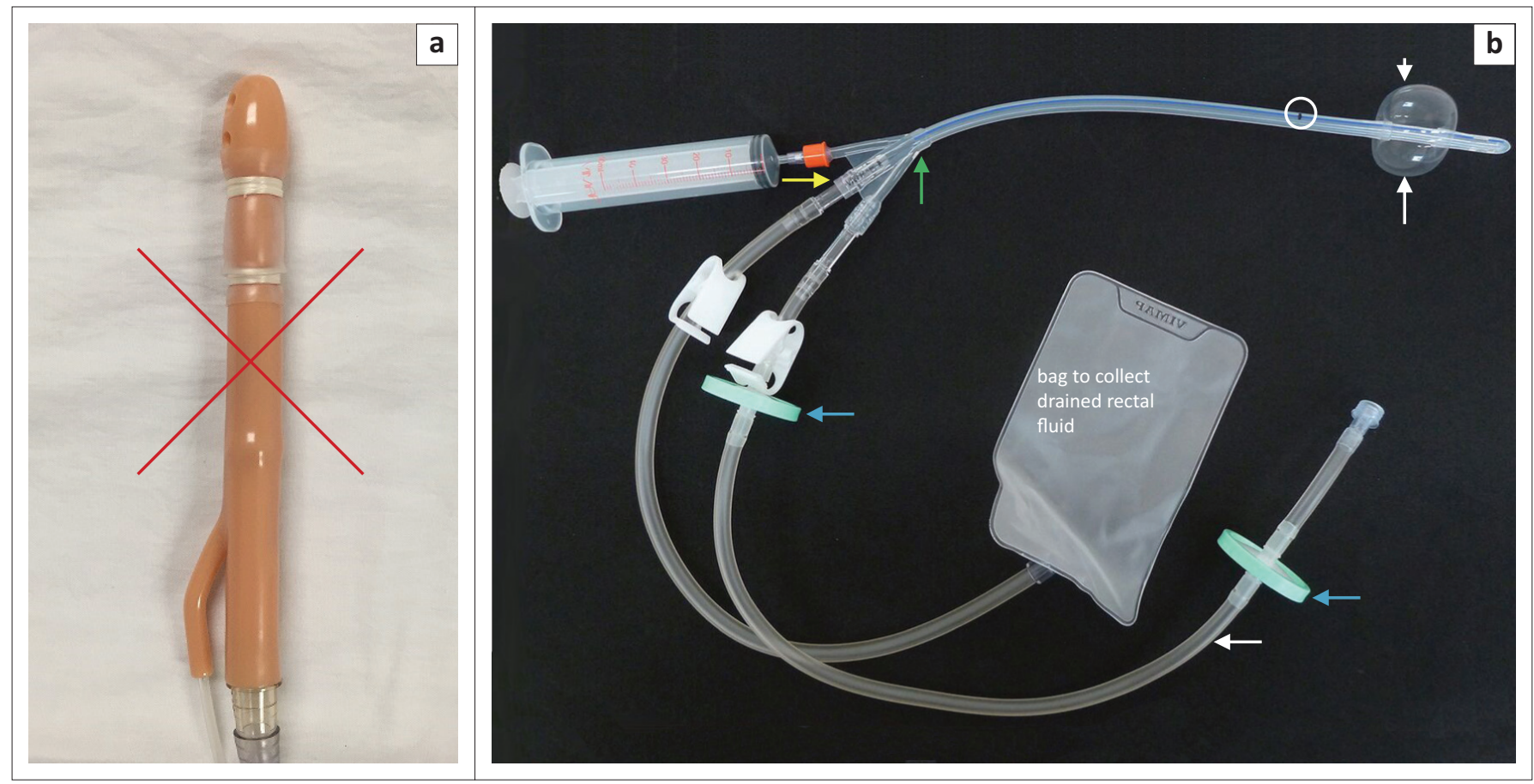

FIGURE 3: (a) Hard catheter is unsuitable as it may cause perforation; (b) Green arrow indicates trifurcation of tube and attached syringe for balloon distension; Yellow arrow indicates rectal drainage bag. White arrow indicates connection to $\mathrm{CO}_{2}$ insufflator. White circle shows black indicator line. The catheter must not be inserted into the rectum beyond the black line (white circle). Inflated balloon (white arrows). Blue arrows indicate two green filters to trap any faecal fluid from entering and contaminating the $\mathrm{CO}_{2}$ insufflator. 

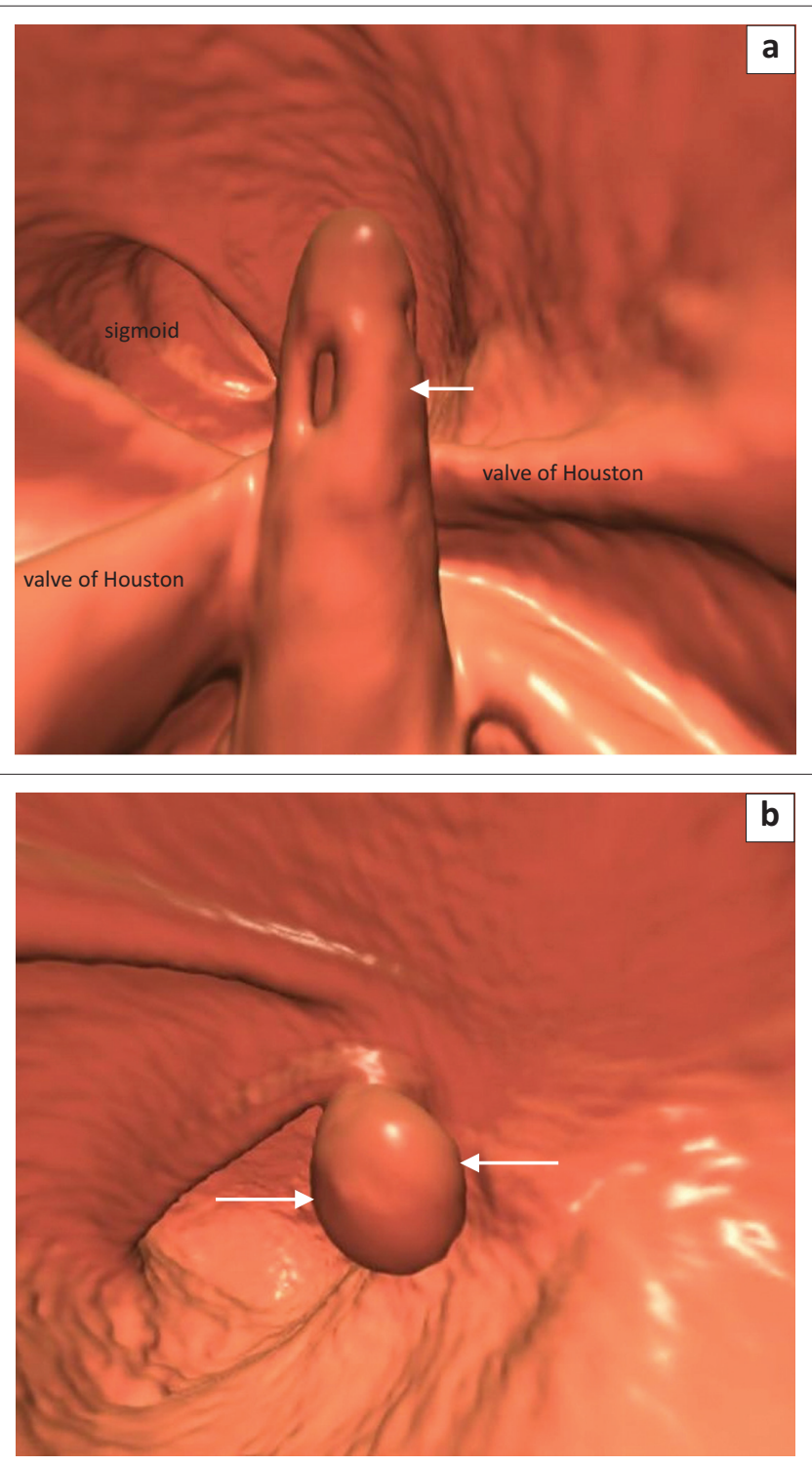

FIGURE 4: (a) 3D image shows the tip of catheter (white arrow) extending beyond the superior valve of Houston; (b) 3D image shows tip of catheter projecting beyond the superior valve of Houston causing simulation of polyp appearance (white arrows). from a sessile polyp. ${ }^{16}$ On $2 \mathrm{D}$ views, foci of air may be present in the polypoidal lesion. ${ }^{16}$

It is important to be familiar with the appearance of artefacts; they can obscure lesions or be mistaken for pathology. Hip prosthesis-related artefacts are because of beam hardening and scatter, which cause dark streak artefacts. Software is available to reduce beam hardening effects. ${ }^{17}$ These streaks are between two high attenuation objects, for example, metal or bone, with surrounding bright streaks. ${ }^{15}$ Poor patient positioning could also produce artefacts. Figure 9 shows these types of artefacts. Artefact-related pitfalls are fairly common. Figure 10 illustrates that an air bubble artefact may appear to be a lesion. The 'dense waterfall' sign (Figure 11) is an artefact that is related to actively flowing opacified luminal fluid. ${ }^{18}$ Although this appearance is rarely seen in the rectum, it is fairly commonly seen in the other five colon segments.

\section{Pathology-related pitfalls}

Internal haemorrhoids are the most frequently seen and diagnosed condition affecting the anorectal region. ${ }^{14}$ They may appear polypoid or mass-like when thrombosed or advanced. ${ }^{4}$ Haemorrhoids are the result of dilated vascular channels above the dentate line (Figure 12). Rectal varices, in contrast to haemorrhoids, have a tubular, serpiginous appearance. ${ }^{2,4}$ Haemorrhoids may be identified on both the prone and supine studies, but in the supine study the inflated rectal balloon may compress internal haemorrhoids, which may make them difficult to diagnose. When the patient is in the prone position, the catheter's balloon should routinely be deflated to decompress internal haemorrhoids, if present, in order to visualise them. . $^{3,6,16}$ Some radiologists do not deflate the balloon for fear that the rectal tube may not remain in situ. The author has hardly ever experienced this happening. The balloon can be re-inflated should there be a need for further views (e.g. lateral decubitus) which require a patient to turn from the

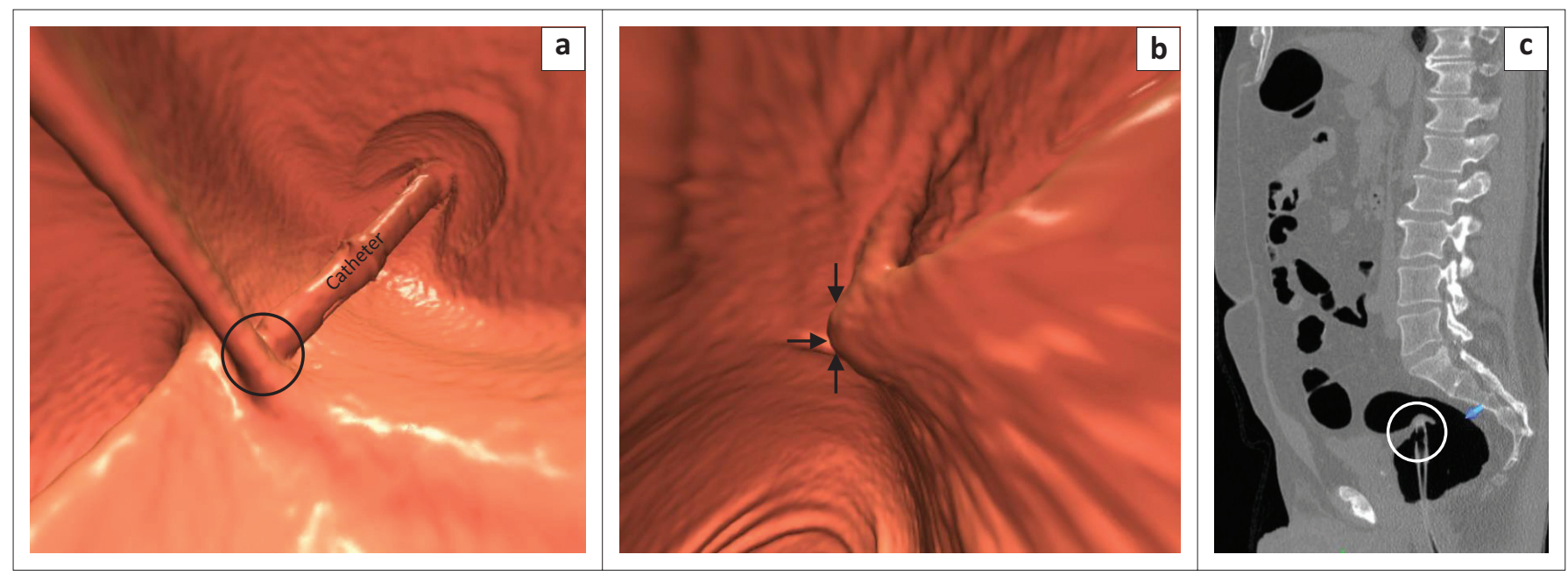

FIGURE 5: (a) 3D endoluminal view showing tube in direct contact with valve of Houston (black circle). (b) 3D endoluminal view showing tube causing a bulge on recta mucosa (black arrows). (c) 2D sagittal view shows tube impinging on fold (white circle). 


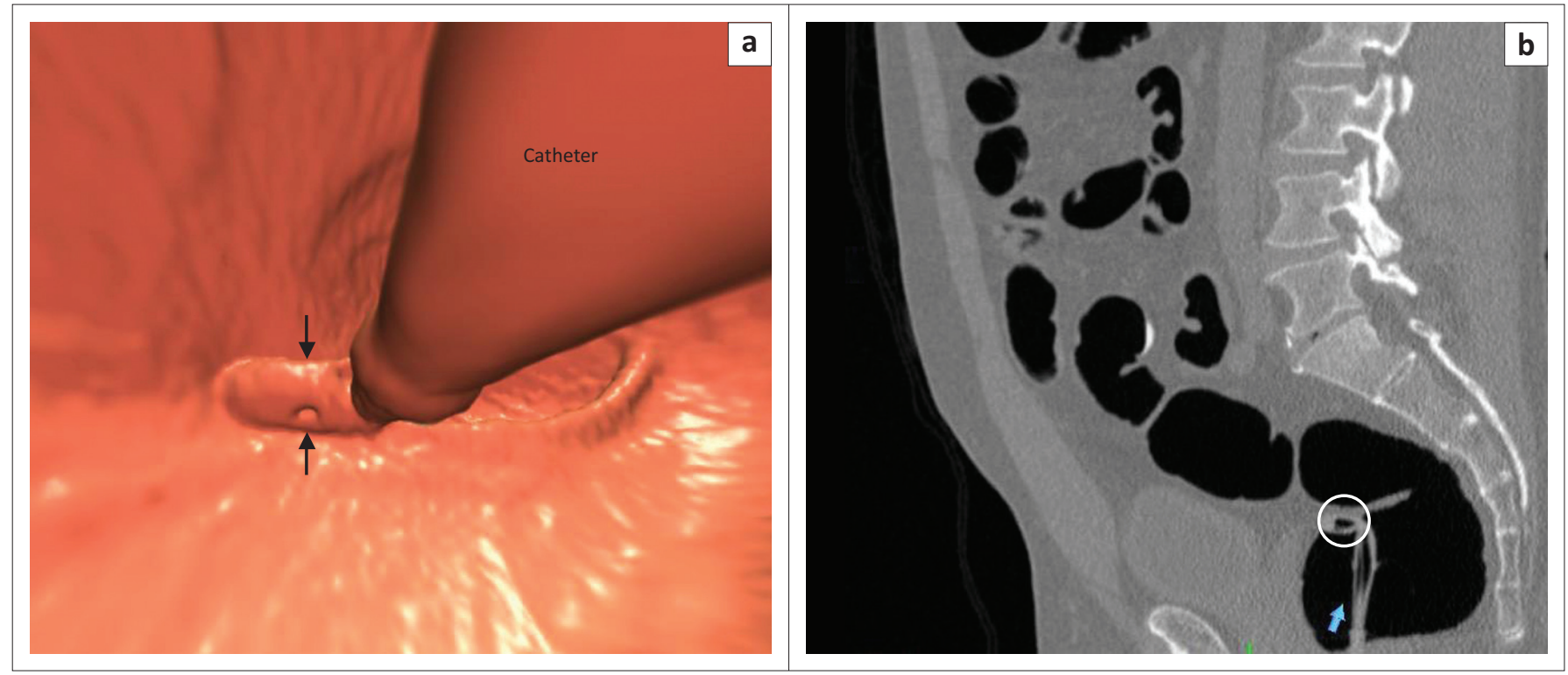

FIGURE 6: (a) 3D view shows kinking of tube (black arrows); (b) 2D view shows tip of rectal tube bent to $90^{\circ}$ (white circle). This obstructs flow of $\mathrm{CO}_{2}$.

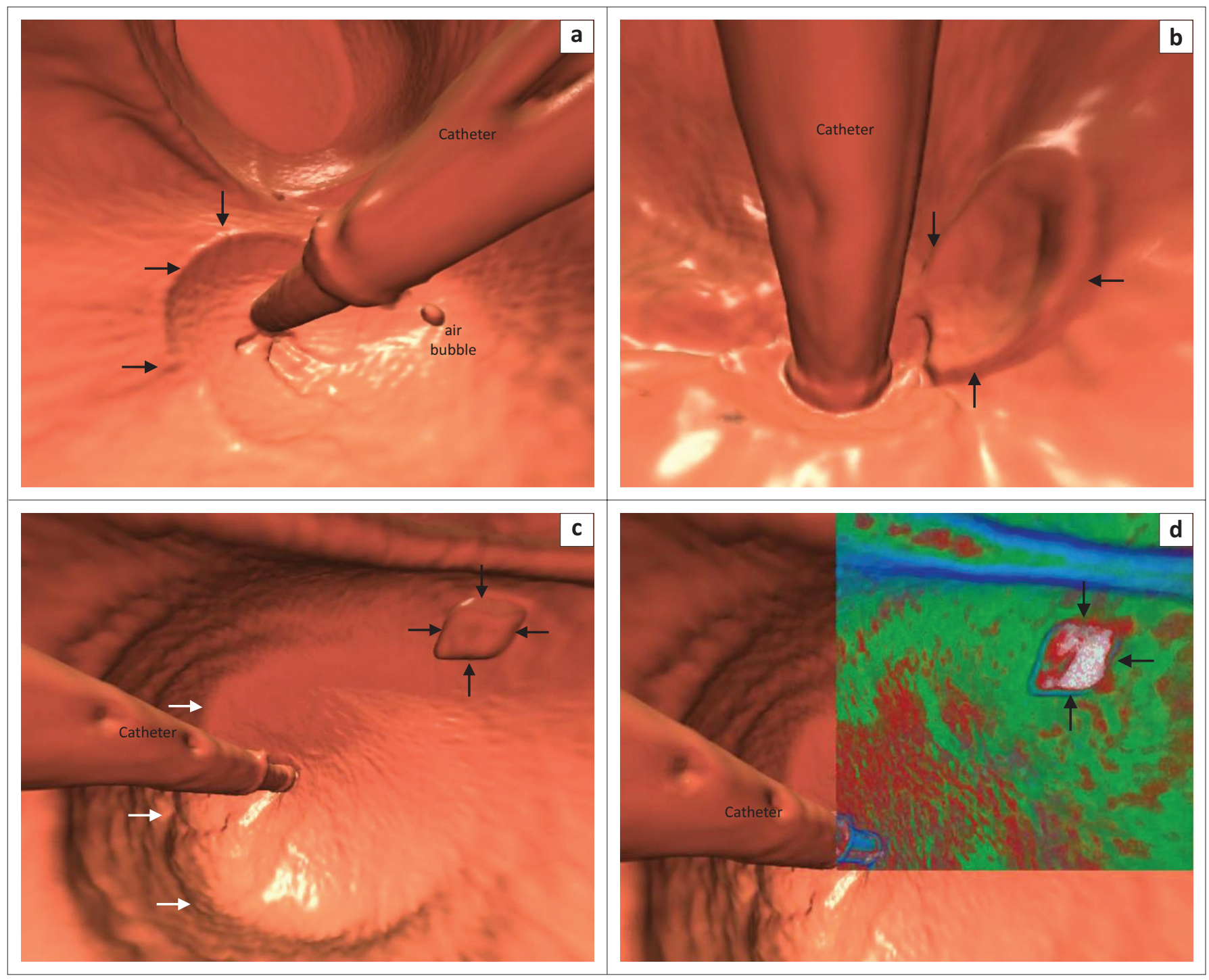

FIGURE 7: (a) 3D view showing meniscal defect (black arrows) due to balloon; (b) 3D view showing meniscal defect (black arrows) from inflated balloon; (c) 3D view showing polypoidal lesion (black arrows). White arrows show margin of meniscal sign; (d) TD shows mainly barium (black arrows) indicating stool. 

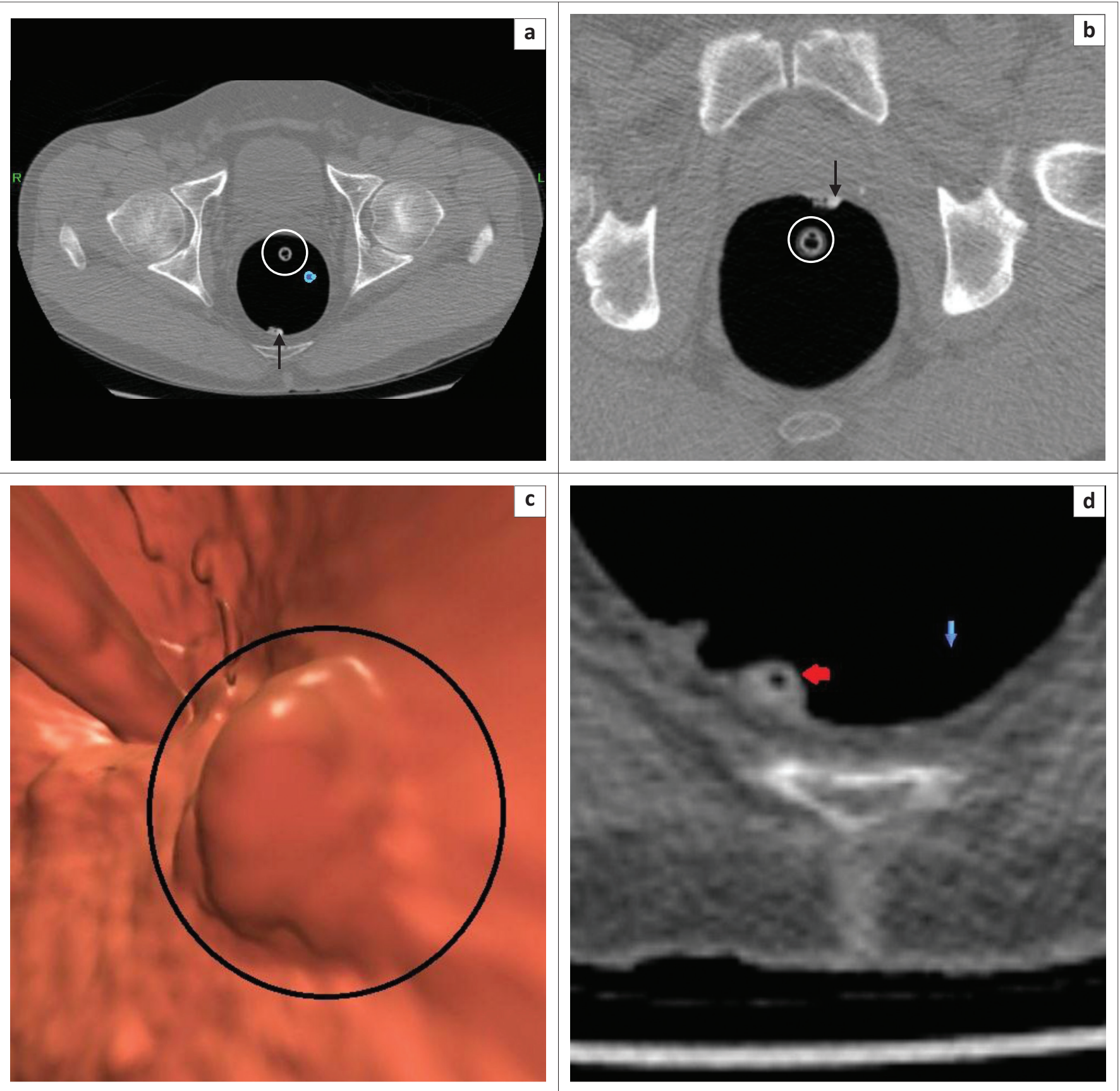

FIGURE 8: (a) 2D supine axial view showing density on posterior wall with lucency within it (black arrow). White circle = rectal catheter; (b) Prone axial study shows the density has shifted to anterior wall indicating stool (black arrow). White circle = rectal catheter; (c) 3D endoluminal view showing polypoidal lesion (black circle); (d) 2D coronal view shows air (red arrow) which indicates the lesion is stool.

prone position. ${ }^{16}$ Figure 13 presents examples of the importance of deflating the balloon in the prone study for visualisation of internal haemorrhoids.

Internal haemorrhoids may be confused with a hypertrophied anal papilla, a benign condition occurring in response to chronic irritation or anal fissuring. ${ }^{3}$ It is essentially an internal skin tag, which represents focal fibrous prominence of tissue at the dentate line. ${ }^{3}$ Anal papillae are small, usually $<6 \mathrm{~mm}$ in size. They are usually single, but multiple papillae have been reported; occasionally, they may be polypoidal in appearance. ${ }^{3}$ The diagnosis of an anal papilla is made by its consistent anatomic position at the anorectal junction. In the vast majority of cases, the papilla is in contact with the rectal tube at its lowest visualised point. When considering whether a polypoidal mass is an anal papilla or a rectal polyp, the clue is their respective location in relation to the catheter (Figure 14). A polyp would be a short distance from the catheter.

Polyps may be sessile or pedunculated. On 3D, they present as polypoid lesions, and they are homogeneous on 2D. Sessile polyps do not move and usually have a thin covering of barium on their surface. The shape and form of flat lesions and carpet lesions are potential pitfalls. ${ }^{19}$ A study is considered positive when a lesion $\geq 6 \mathrm{~mm}$ is detected. Polyps $\geq 10 \mathrm{~mm}$ are routinely removed. The chance of malignancy is $<1 \%$ in 

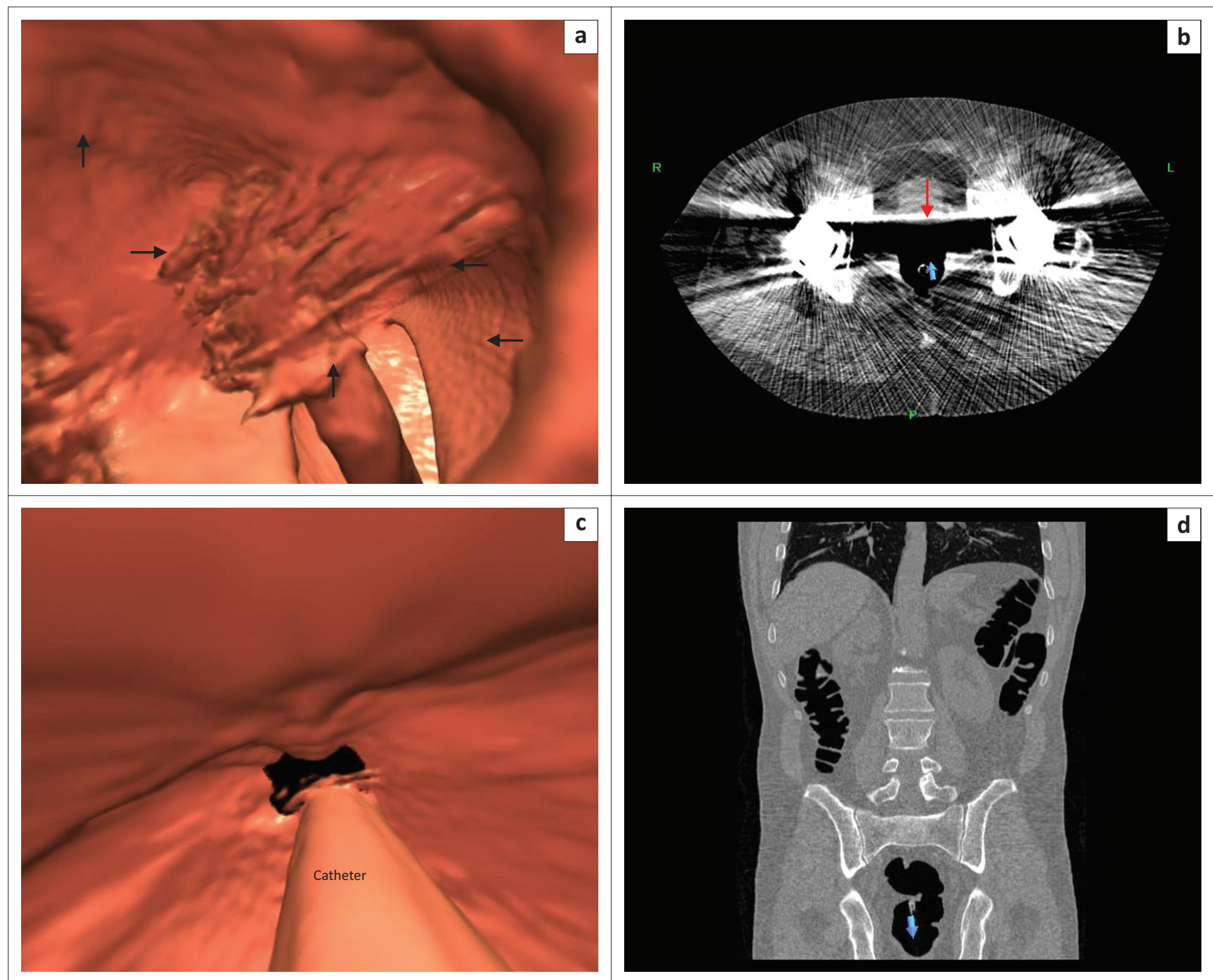

FIGURE 9: (a) 3D endoluminal view showing artefacts (black arrows) obscuring visualisation of the rectum; (b) 2D axial of the same patient shows streak artefacts limiting visualisation of colon (red arrow). This is a typical example of artefacts caused by hip prostheses; (c) 3D view shows 'black hole' artefact. It represents an absence of data due to poor patient positioning, which caused cut-off related to incomplete scanning; (d) Coronal view shows incorrect positioning of the patient as the symphysis pubis is not included. Correct patient positioning must include $3 \mathrm{~cm}$ below symphysis pubis and $3 \mathrm{~cm}$ above the diaphragm.
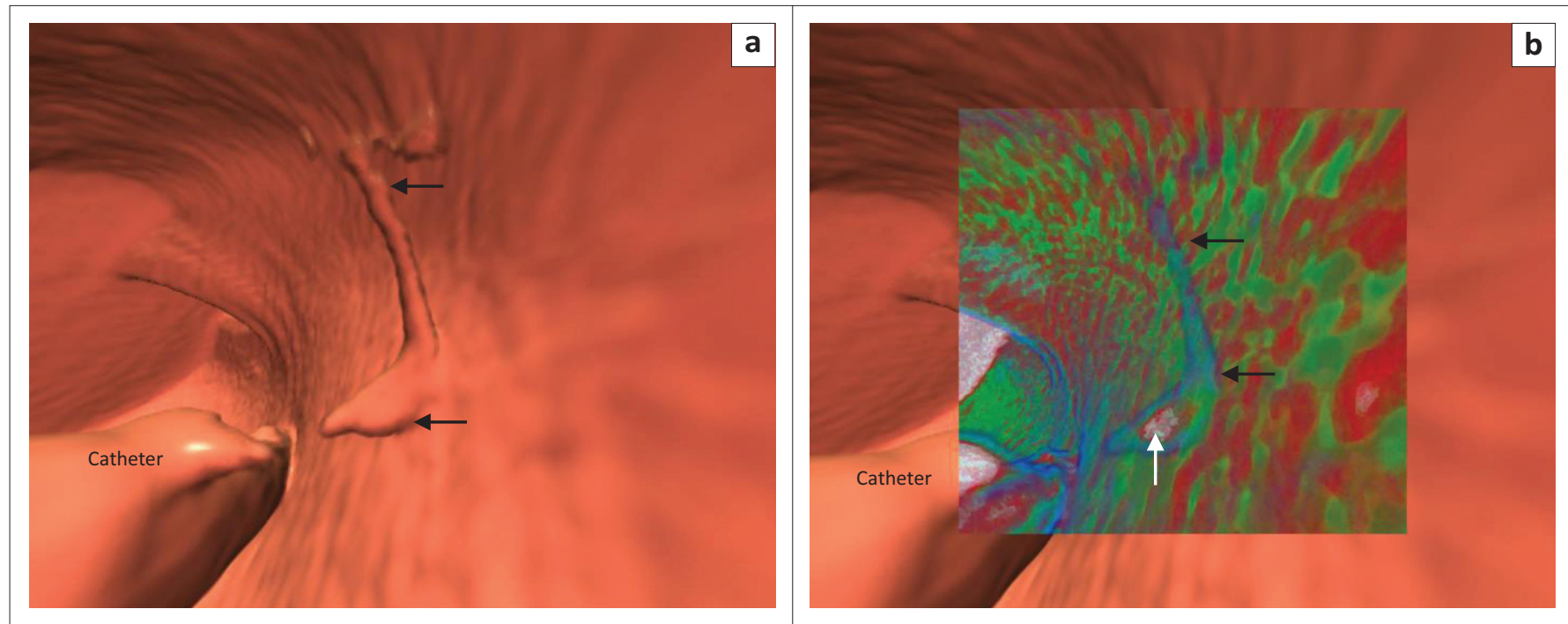

FIGURE 10: (a) 3D view shows curvilinear density indicating an artefact (black arrows); (b) TD shows thin blue line (black arrows) with a small blob of barium (white arrow) inferiorly indicating barium and air artefact. 

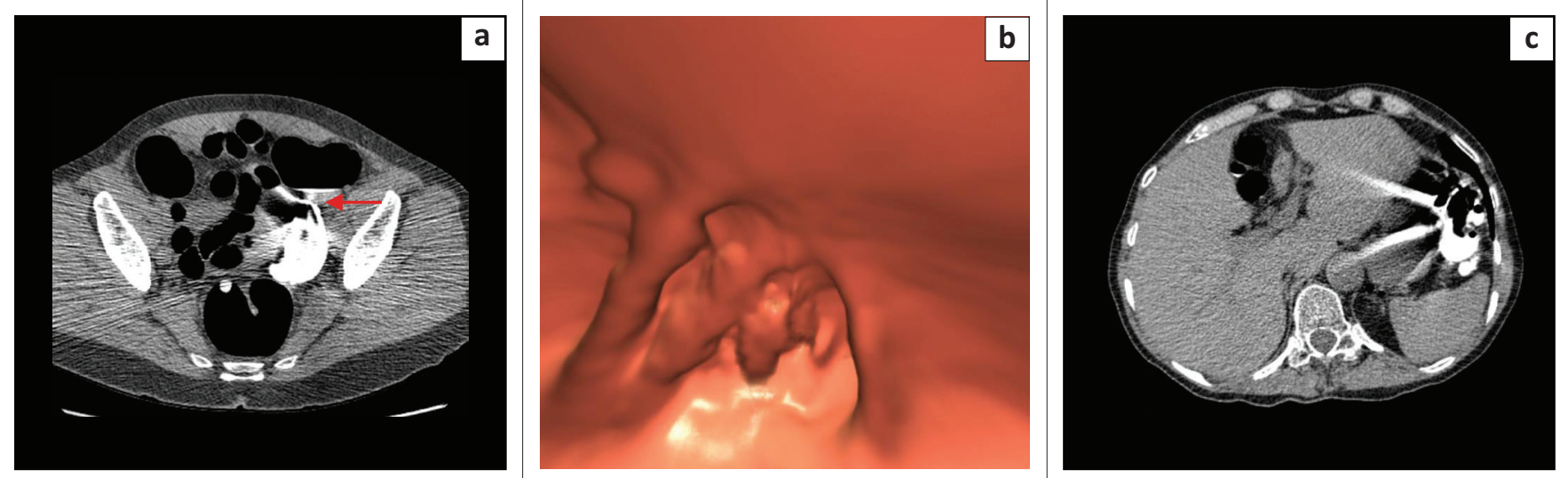

FIGURE 11: (a) Dense 'waterfall sign' in the rectosigmoid region, caused by flowing fluid (red arrow) during the scan process; (b) 3D endoluminal view showing artefact from fluid movement; (c) Dense waterfall sign in descending colon showing classical streak artefact because of fluid movement.

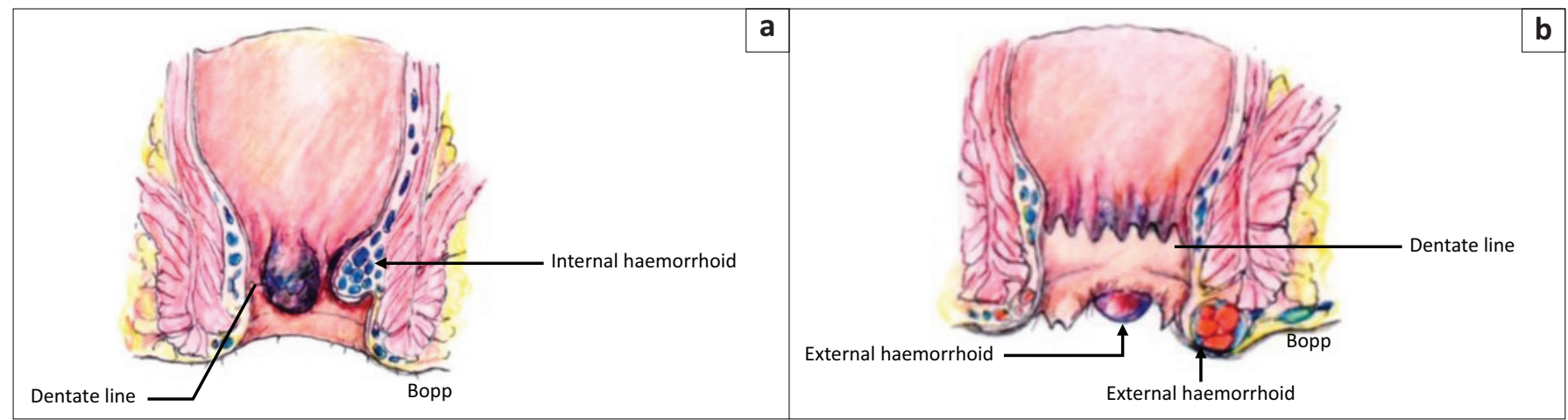

Source: Adapted from Netter F. The Ciba collection of medical illustrations. Vol 3. Digestive system. Part 2. Lower digestive tract. New York: Colour Press, 1962, p 58

FIGURE 12: (a) Internal haemorrhoid above the dentate line and (b) external haemorrhoids.
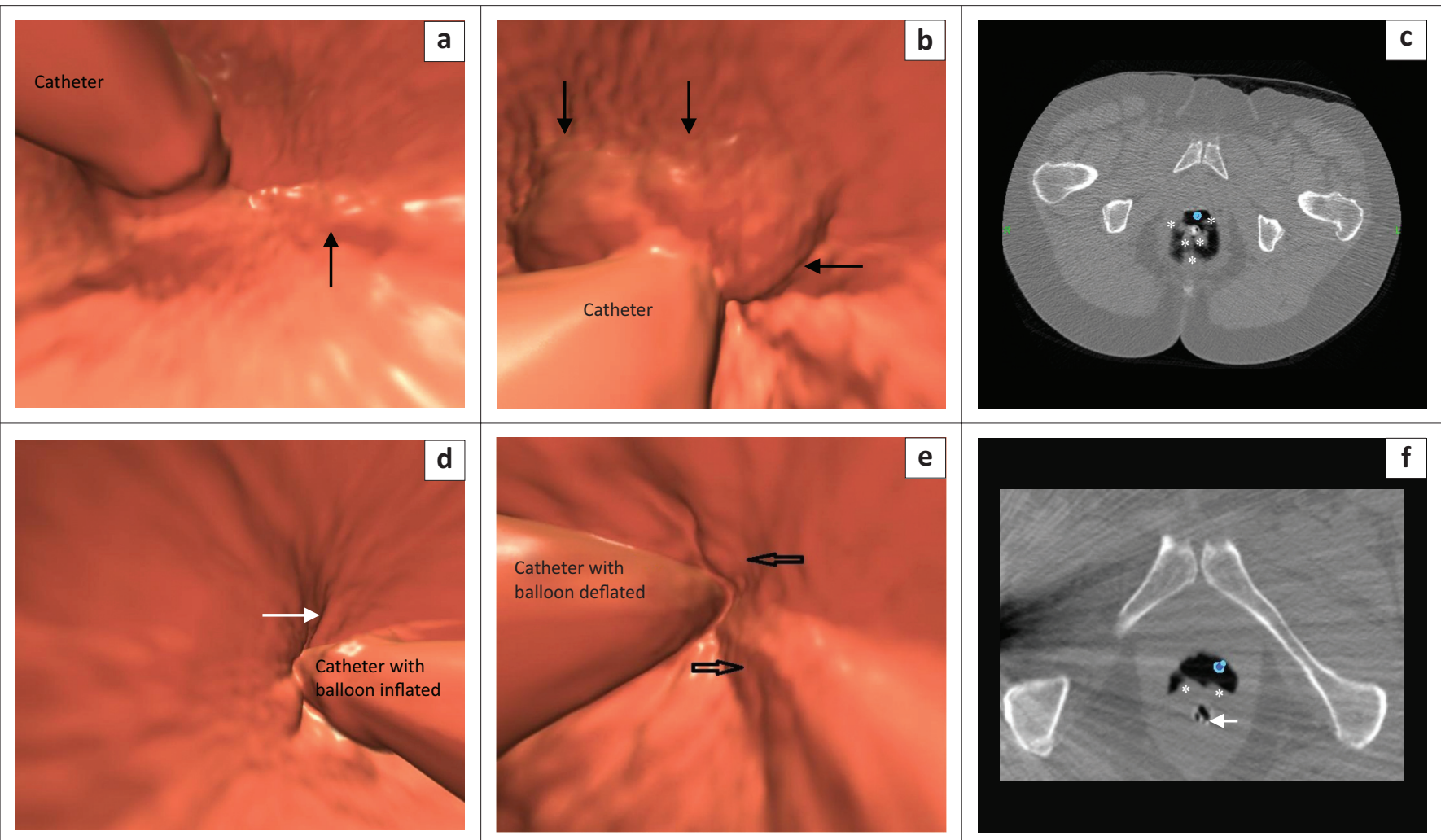

FIGURE 13: (a) Supine 3D view with inflated balloon showing internal haemorrhoid (black arrow); (b) Prone 3D view with deflated balloon showing polypoidal haemorrhoids (black arrows); (c) Prone 2D axial view with deflated balloon showing large haemorrhoids (*); (d) 3D supine view of inflated balloon. Internal haemorrhoid (white arrow); (e) 3D prone view with deflated balloon shows internal haemorrhoids more prominently (black arrows); (f) 2D axial view with deflated balloon (white arrow) showing internal haemorrhoids $(*)$. White arrow indicates the placement of the catheter. 
an asymptomatic low-risk individual (Figure 15). ${ }^{3}$ Large advanced adenomas (> $10 \mathrm{~mm}$, large polyp) represent the key target sign for CRC screening and prevention; they are at higher risk for cancer progression. ${ }^{3,20}$ Between $90 \%$ and $95 \%$ of advanced adenomas are $10 \mathrm{~mm}$ or larger in size, but only adenomas and serrated polyps have the possibility of future transformation into cancers. ${ }^{21}$

Flat lesions are usually $<30 \mathrm{~mm}$ in size and are elevated approximately $3 \mathrm{~mm}$ above the colonic mucosa. They are a

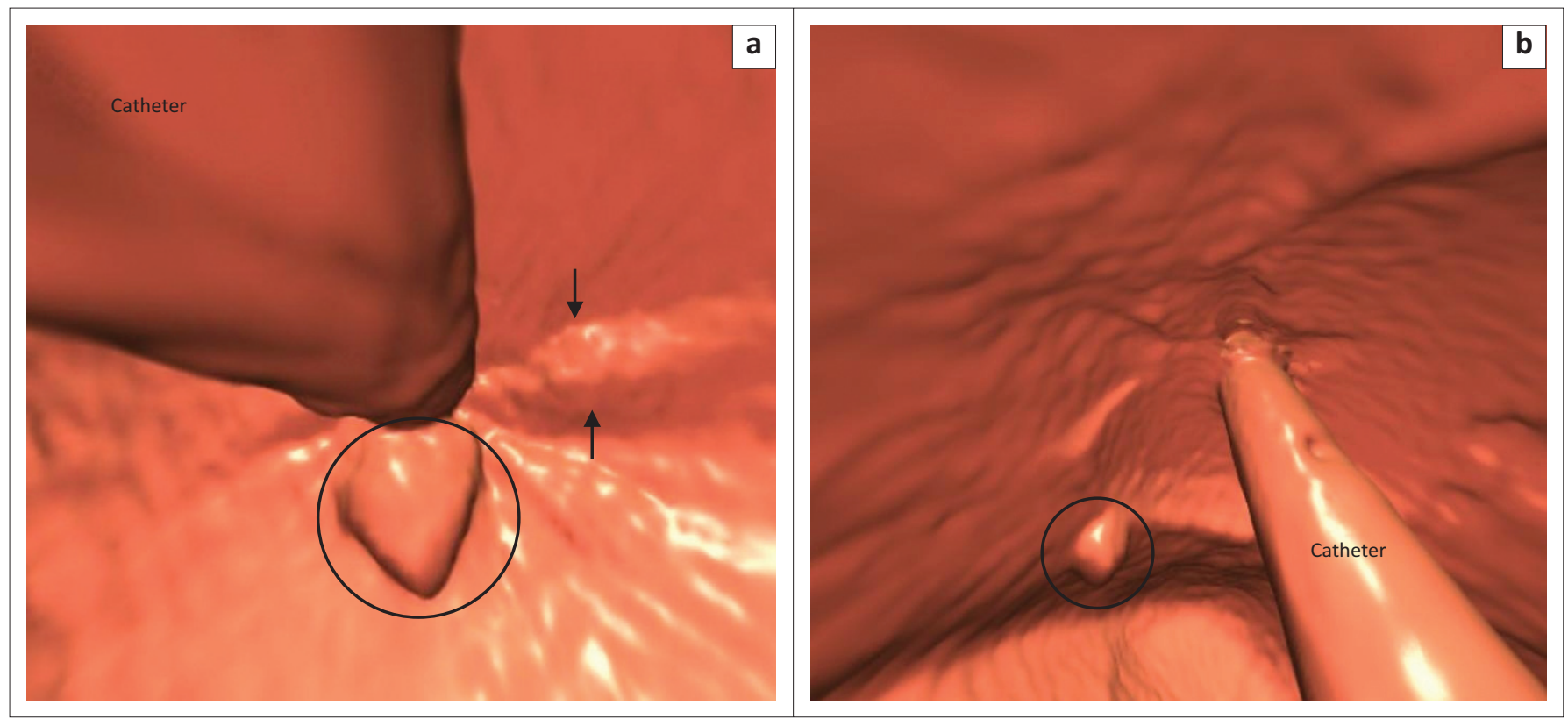

FIGURE 14: (a) 3D image showing linear internal haemorrhoids (black arrows) and anal papilla (circle) in close proximity to the catheter; (b) 3D image of a polyp (circle) away from the catheter.
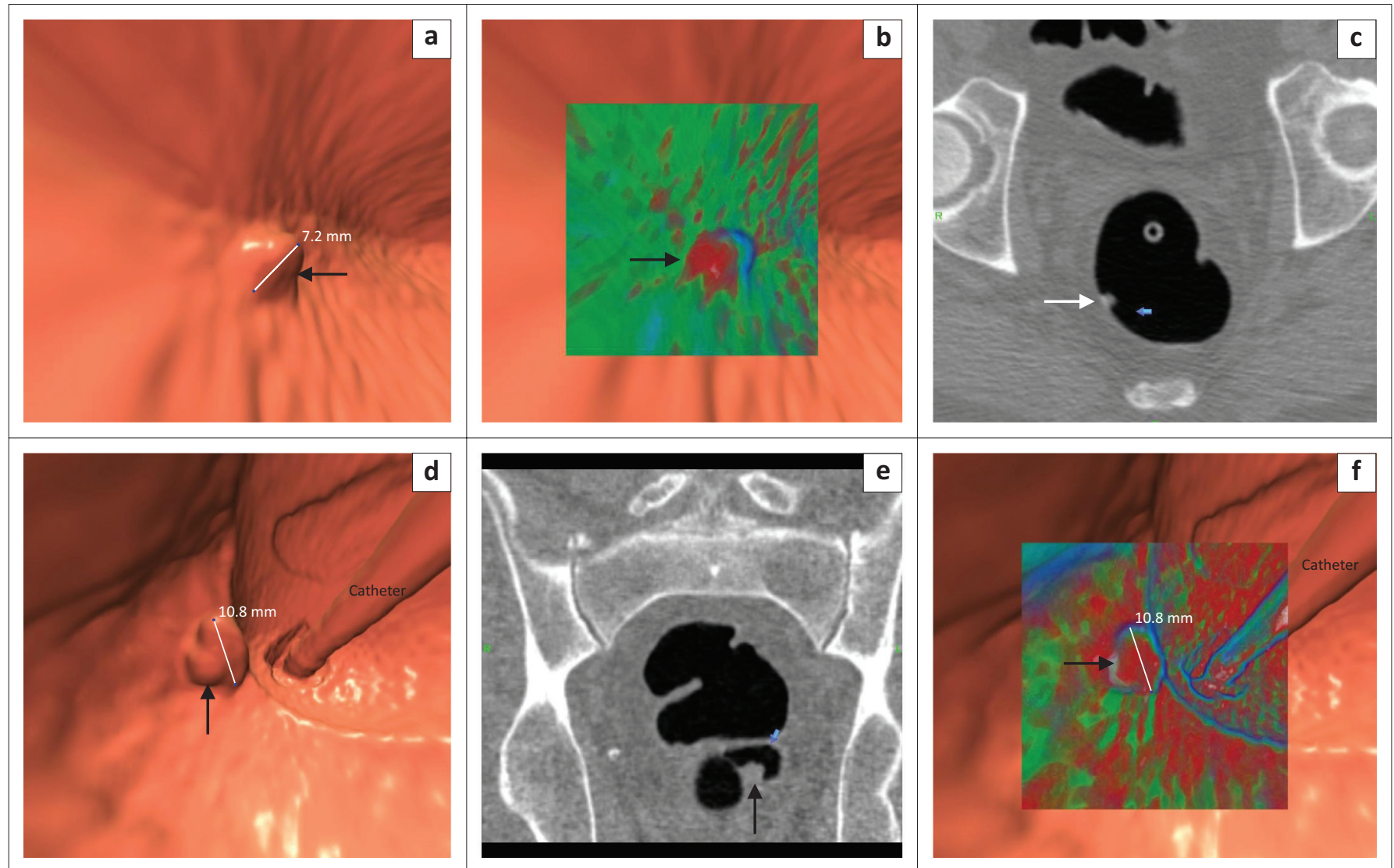

FIGURE 15: (a) 3D view showing $7 \mathrm{~mm}$ sessile polyp (black arrow); (b) TD showing predominantly red = soft tissue (black arrow) indicating polyp; (c) 2D axial supine view shows homogenous polypoidal density in keeping with a polyp (white arrow); (d) 3D endoluminal view showing an 11 mm polypoid lesion (black arrow); (e) 2D axial view showing homogenous lesion (black arrow); (f) TD showing predominantly red = soft tissue (black arrow) compatible with an advanced adenoma. 


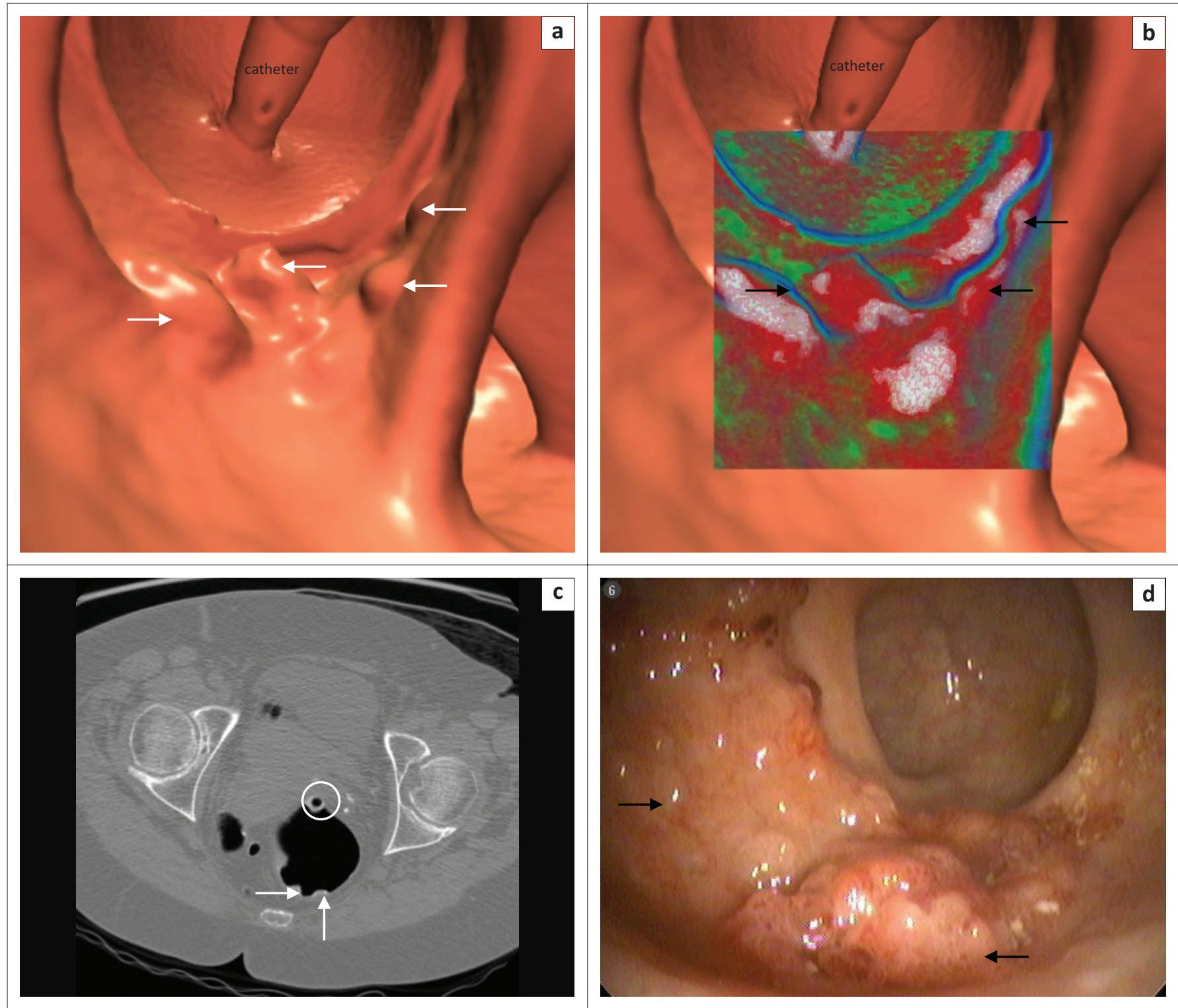

Source: Courtesy of Prof. D. Kim, Wisconsin University.

FIGURE 16: (a) 3D endoluminal view of rectum showing rectal catheter and carpet lesion extending for $40 \mathrm{~mm}$ (white arrows). Histology confirmed tubulovillous adenoma; (b) TD view showing rectal catheter and lobulated high intensity regions (black arrows) covered with a thin layer of barium (white); (c) 2D axial view of rectum with rectal catheter (white circle). Polyp view showing flat soft tissue lesion (white arrows). Note the etching of positive contrast material on the surface of the lesion; (d) Optical colonoscopy view confirms CTC finding of a minimally raised somewhat lobulated carpet lesion in the rectum (black arrows).
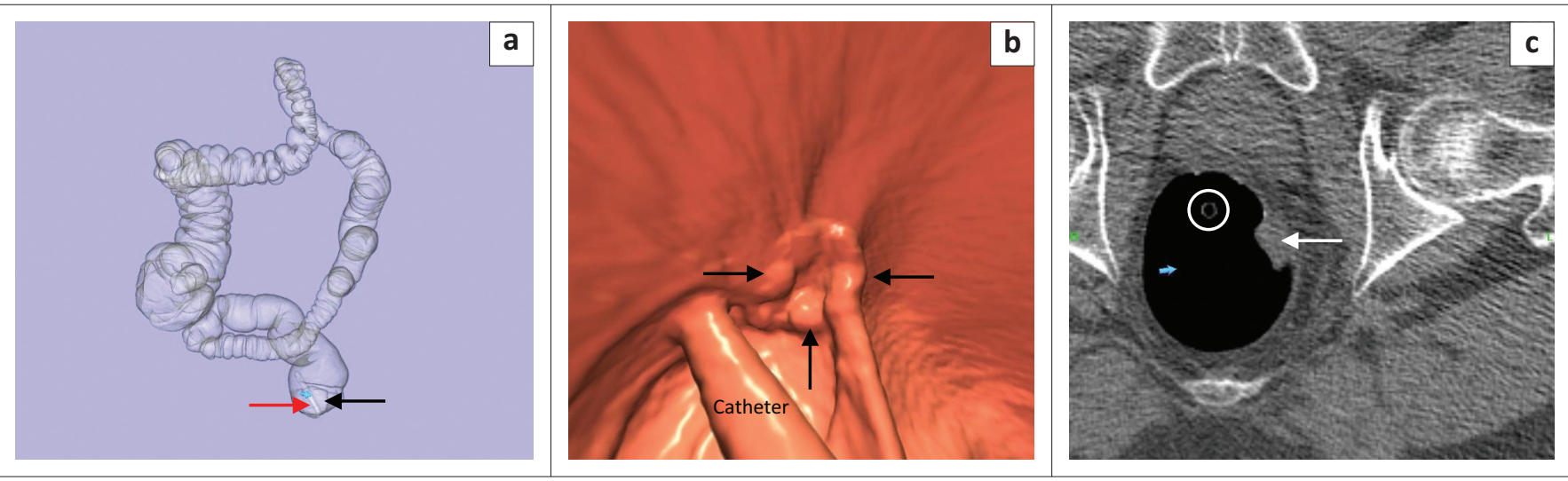

FIGURE 17: (a) Prone colon-map showing left rectal wall lesion (black arrow). Rectal catheter (red arrow); (b) 3D view of an irregular polypoidal lesion in rectum in keeping with cancer (black arrows); (c) 2D axial image shows catheter (white circle) and soft tissue mass with thickening of the left rectal wall in keeping with cancer (white arrow). 
subset of sessile polyps that do not have a polypoidal appearance ${ }^{22}$ and occur most commonly in the rectum and caecum. If they are $\geq 30 \mathrm{~mm}$ in size, they are termed carpet lesions (Figure 16) or laterally spreading tumours..$^{23}$ Despite their large size, carpet lesion histology is usually a villous adenoma or tubulovillous adenoma. High-grade dysplasia may also be present. Malignancy is not a common finding in carpet lesions. ${ }^{19,23}$

When evaluating anorectal CTC images, we need to consider the possibility of a malignant lesion. A cancer has an irregular polypoid appearance with thickening of the bowel wall. Figure 17 shows rectal cancer. Rectal tumours may be aggressive in immunocompromised patients, particularly those who have the acquired immunodeficiency syndrome. ${ }^{3}$

We need to be mindful of possible perforations caused by diagnostic and therapeutic procedures at OC..$^{7,24,25}$ Direct mechanical trauma may be caused by injury to the colon by the end of the endoscope, or from the abrasive effect of the side of the scope as it is advanced or withdrawn. ${ }^{24}$ In the rectum, the colonoscope may be retroflexed; this may

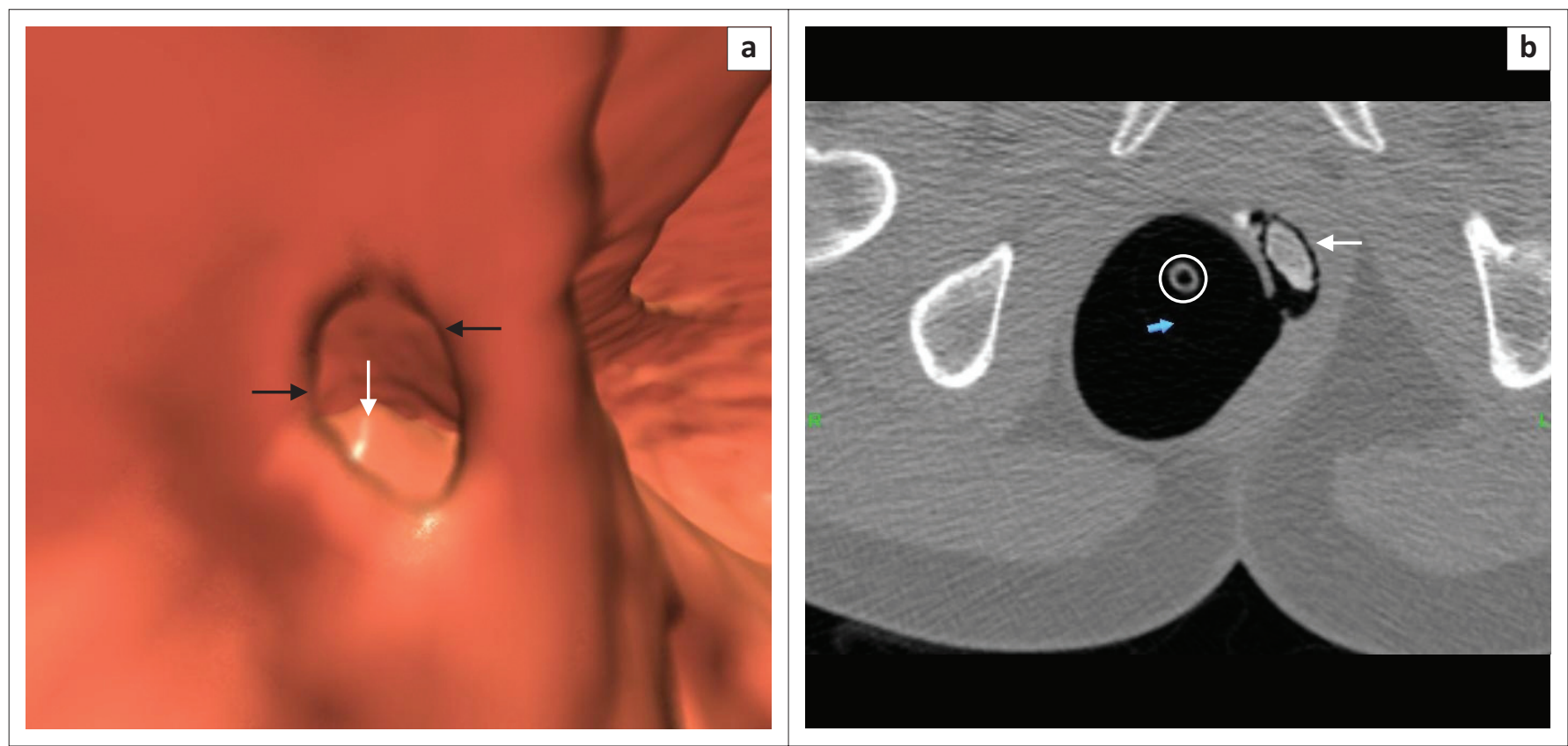

FIGURE 18: (a) 3D view of a 'contained' perforation of rectum (black arrows). Calcified enterolith (white arrow); (b) 2D axial view shows a 'contained' perforation and calcified faecalith (white arrow) and rectal catheter (white circle).

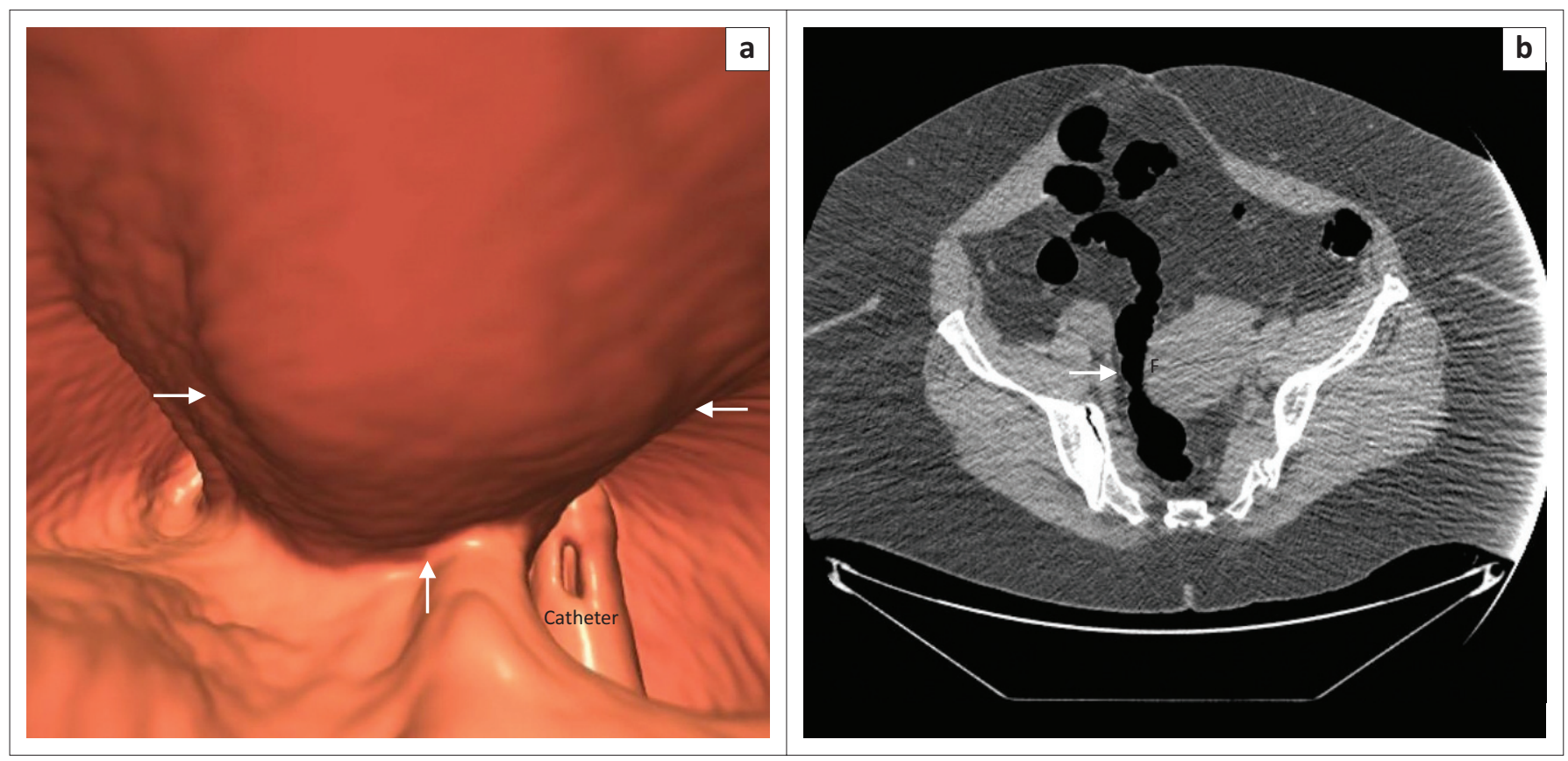

FIGURE 19: (a) 3D view showing an extrinsic impression from a pedunculated uterine fibroid (arrows); (b) 2D axial showing pedunculated uterine fibroid (F) causing narrowing of rectum (white arrow). 
result in a single 'contained perforation', which may be complicated by faecolith formation (Figure 18). Before commencing a CTC following an incomplete or failed OC, it is essential to exclude perforation. A pre-procedure lowdose CT scan is performed to assess whether free air is present, and if visualised, the CTC study is not performed..$^{16}$ Risk of colonic perforation during CTC is rare because of the use of automatic insufflation and a small gauge soft rectal catheter. ${ }^{16,25,26}$

Any structure that lies adjacent to the colon may cause an extrinsic impression on the colon lumen. ${ }^{14}$ These impressions are easily identifiable when $2 \mathrm{D}$ multiplanar reformation is performed. The most common sources of these impressions include the uterus and adnexa (Figure 19).

\section{Conclusion}

Potential anorectal region pitfalls may be related to technique, interpretation or specific anatomical features. ${ }^{2,3,4}$ Knowledge of these potential pitfalls should prevent CTC readers from missing cancers and avoid misdiagnosis of benign lesions.

\section{Acknowledgements}

Clinton Bopp is thanked for drawing the line diagrams of the anatomy of the rectum and internal haemorrhoids. Professor D Kim, Wisconsin University, is thanked for the carpet lesion images. Mrs. Leonie Munro for assisting with the editing and proofreading of this article.

\section{Competing interests}

The author declares that he has no financial or personal relationships which may have inappropriately influenced him in writing this article.

\section{References}

1. Bibbins-Domingo K, Grossman DC, Curry SJ, et al. Screening for colorectal cancer: US Preventive Services Task Force Recommendation Statement. JAMA. 2016;315:2564-2575. https://doi.org/10.1001/jama.2016.5989

2. Lefere P, Gryspeerdt S. CT colonography: Avoiding traps and pitfalls. Insights Imaging. 2011;2:57-68. https://doi.org/10.1007/s13244-010-0054-3

3. Pickhardt PJ. Screening CT colonography: How I do it. AJR. 2007;189(2):290-298. https://doi.org/10.2214/ajr.07.2136

4. Pickhardt PJ, Kim DH. CT colonography: Pitfalls in interpretation. Radiol Clin North Am. 2013;51:69-88. https://doi.org/10.1016/j.rcl.2012.09.005
5. Spada C, Stoker J, Alarcon O, et al. Clinical indications for computed tomographic colonoscopy: European Society of Gastrointestinal Endoscopy (ESGE) and European Society of Gastrointestinal and Abdominal Radiology (ESGAR) guideline. Eur Radiol. 2015;25:331-345. https://doi.org/10.1007/s00330-014-3435-z

6. Pickhardt PJ. Differential diagnosis of polypoidal lesions seen at CT colonography (virtual colonoscopy). RadioGraphics. 2004;24(6):1535-1556. https://doi. org/10.1148/rg.246045063

7. Kim DH, Pickhardt PJ, Taylor AJ, Menias CO. Imaging evaluation of complications at optical colonoscopy. Curr Probl Diagn Radiol. 2008;37:165-177. https://doi. org/10.1067/j.cpradiol.2007.10.004

8. Daly B, Lu M, Pickhardt PJ, Menias CO, Abbas MA, Katz DS. Complications of optical colonoscopy: CT findings. Radiol Clin North Am. 2014;52:1087-1099. https://doi. org/10.1016/j.rcl.2014.05.012

9. Bortz JH. СTC technique and methods of interpreting images. In: Bortz JH et al., editors. CT colonography for radiographers: A guide to performance and image interpretation. Basel: Springer; 2016; p. 103-123.

10. Netter F. The Ciba collection of medical illustrations. Volume 3. Digestive system. Part 2. Lower digestive tract. New York: Colour Press; 1962; p. 58.

11. Abramson DJ. The valves of Houston in adults. Am J Surg. 1978;c136:334-336.

12. Pickhardt PJ, Choi JR. Adenomatous polyp obscured by small-caliber rectal catheter at low-dose CT colonography: A rare diagnostic pitfall. AJR 2005;184:1581-1583. https://doi.org/10.2214/ajr.184.5.01841581

13. Macari M, Bini EJ. CT colonography: Where have we been and where are we going? Radiology. 2005;237:818-833. https://doi.org/10.1148/radiol.2373041717

14. Pickhardt PJ, Kim DH. CT colonography: Principles and practice of virtual colonoscopy. Philadelphia, PA: Saunders; 2009; p. 213-214, 312.

15. Boas FE, Fleischmann D. CT artefacts: Causes and reduction techniques. Imaging Med. 2012;4(2):229-240. https://doi.org/10.2217/iim.12.13

16. Bortz JH. CT colonography: An approach for a successful examination. S Afr J Rad. 2014;18(1). http://dx.doi.org/10.4102/sajr.v18i1.607

17. Bannas $P$, Li $Y$, Motosugi $U$, et al. Prior image constrained compressed sensing metal artifact reduction (PICCS-MAR): 2D and 3D image quality improvement with hip prostheses at CT colonography. Eur Radiol. 2016;26(7):2039-2049. https:// doi.org/10.1007/s00330-015-4044-1

18. Boyce CJ, Vetter JR, Pickhardt PJ. MDCT artefact related to the intra-scan gravitational flow of opacified luminal fluid (the "Dense Waterfall" sign) Abdominal Imaging. 2012;37(2):292-296. https://doi.org/10.1007/s00261-011 9731-z

19. Galdino GM, Yee J. Carpet lesion on CT colonography: A potential pitfall. AJR 2003;180:1332-1334. https://doi.org/10.2214/ajr.180.5.1801332

20. Pickhardt PJ, Kim DH. Colorectal cancer screening with CT colonography: Key concepts regarding polyp prevalence, size, histology, morphology, and natural history. AJR. 2009;193:40-46. https://doi.org/10.2214/AJR.08.1709

21. Kim DH, Pickhardt PJ, Taylor AJ, et al. CT colonography versus colonoscopy for detection of advanced neoplasia. N Eng J Med. 2007;357(14):1403-1412. https:// doi.org/10.1056/NEJMoa070543

22. Yee J, Chang KJ, Dachman AH, et al. The added value of the CT colonography reporting and data system. JACR. 2016;13(8):931-935. https://doi.org/10.1016/j. jacr.2016.04.031

23. Pickhardt PJ, Lam VP, Weiss JM, et al. Carpet lesions detected at CT colonography: Clinical, imaging, and pathologic features. Radiology. 2014;270:435-443. https:// doi.org/10.1148/radiol.13130812

24. Bortz JH. Introduction. In: Bortz JH et al., editors. CT colonography for radiographers: A guide to performance and image interpretation. Basel: Springer; 2016; p. 1-8.

25. Pickhardt PJ. Incidence of colonic perforation at CT colonography: Review of existing data and implication for screening of asymptomatic adults. Radiology. 2006;239(2):313-316. https://doi.org/10.1148/radiol.2392052002

26. Neri E, Halligan S, Hellström M, et al. The second ESGAR consensus statement of CT colonography. Eur Radiol. 2013;23:720-729. https://doi.org/10.1007/s00330$012-2632-x$ 